\title{
COMPUESTOS SINTAGMÁTICOS Y COMBINACIONES FRECUENTES EN LA CONFIGURACIÓN DEL TECNOLECTO MATEMÁTICO DEL QUINIENTOS: EL CASO DE REGLA Y SU RED LÉXICA
}

\author{
Itziar Molina Sangüesa \\ Universidad de Salamanca \\ itziarmolina@usal.es
}

\begin{abstract}
RESUMEN: Ante la necesidad de expresar o vehicular conocimientos y conceptos trasmitidos en latín, hasta la centuria quinientista, a una minoritaria élite culta, comprobaremos que la voz regla se erige como un núcleo rentable y productivo en la génesis de diversas expresiones en español relativas a la aritmética y el álgebra. Presentamos en este estudio una veintena de formaciones romances pertenecientes al Glosario de aritmética y álgebra en el Renacimiento hispano, integrado en la actualidad en el Diccionario de la Ciencia y de la Técnica del Renacimiento (DICTER), mediante las que estudiamos algunos de los mecanismos o procedimientos morfológicos que intervienen en la configuración del tecnolecto matemático.
\end{abstract}

PALABRAS CLAVE: lexicología histórica, morfología, compuestos sintagmáticos, tecnolecto aritmético-algebraico, Renacimiento.

\section{SYNTAGMATIC COMPOUNDS AND FREQUENT COMBINATIONS IN THE CONFIGURATION OF THE MATHEMATICAL TECHNOLECT OF THE FIFTEENTH CENTURY: THE WORD REGLA AND ITS LEXICAL NET}

\begin{abstract}
In the face to the need to express knowledge and concepts to the time transmitted in Latin to a minority elite, we will verify that the spanish word regla stands as a profitable and productive nucleus in the genesis of diverse expressions in Spanish related to arithmetic and algebra. In this study we present some twenty romances formations belonging to the Glosario de aritmética y álgebra en el Renacimiento hispano, currently integrated into the Diccionario de la Ciencia y de la Técnica del Renacimiento (DICTER), through which we study the
\end{abstract}


mechanisms or procedures morphological that intervene in the configuration of the spanish mathematical technolect.

KEYWORDS: historic lexicology, morfology, sintagmatic compounds, arithmetic-algebraic technolect, Renaissance.

\title{
COMPOSES SYNTAGMATIQUES ET COMBINAISON FREQUENTES DANS LA FORMATION DU TECHNOLECTE MATHEMATIQUE DU XVE SIECLE : LE CAS DU MOT REGLA ET DE SON RESEAU LEXICAL
}

\begin{abstract}
RÉSUMÉ : Pour répondre aux besoins d'exprimer des connaissances et des concepts transmis en latin jusqu'au $X V^{E}$ siècle à l'élite culte minoritaire, nous allons montrer que le mot regla devient un noyau rentable et productif en ce qui concerne la genèse de plusieurs expressions en espagnol dans le domaine de l'arithmétique et de l'algèbre. Dans cete étude, nous allons présenter une vingtaine de formations romanes appartenant au Glosario de aritmética y álgebra en el Renacimiento hispano, qui fait partie aujourd'hui du Diccionario de la Ciencia y de la Técnica del Renacimiento (DICTER), pour étudier certains procédés morphologiques qui interviennent dans la formation du technolecte mathématique.

MOTS CLÉS : lexicologie historique, morphologie, composés symtagmatiques, technolecte arithmétique-algébrique.
\end{abstract}

Recibido: 24/02/2018. Aceptado: 29/06/2018

\section{Presentación}

El desarrollo y el pragmatismo que supuso la aplicación de las ciencias exactas a otras parcelas del saber en el Renacimiento fue trascendental tanto para el despegue de la ciencia y de la técnica modernas como para la configuración de las bases científicas en Europa. De acuerdo con Maravall (1972: 68), la consolidación del estado moderno no hubiera sido factible sin el triunfo del espíritu de cálculo, que, extendido a todos los ámbitos socio-culturales -en buena medida, gracias a la redacción y divulgación de multitud de tratados consagrados a las cuentas ${ }^{1}-$, trajo consigo un auténtico proceso de aritmetización de la realidad e inspiró una nueva conformación del saber.

1. Como explican Paradis y Malet (1989: 99), "la irreversible ascensión de una clase mercantil directamente ligada a la evolución de los gremios de artesanos más poderosos queda reflejada en la aparición de manuscritos de aritmética y de álgebra en lengua vernácula”. 
Ante la necesidad de transmitir saberes y conceptos hasta el momento expresados en latín y a una minoría, comprobaremos que el término regla se erige como un núcleo rentable y productivo en la creación de varias expresiones en español relativas a la aritmética y el álgebra. Estas abarcan, como justificaremos, desde los conceptos más elementales de aritmética práctica o comercial (a saber: la suma, resta, división y multiplicación) a complejas estructuras algebraicas en las que intervienen una o varias incógnitas.

Ofrecemos en este trabajo un conjunto de más de veinte formaciones romances compiladas en el Glosario de aritmética y álgebra en el Renacimiento hispano (Molina Sangüesa 2015a), que se integra, actualmente, en el Diccionario de la Ciencia y de la Técnica del Renacimiento (DICTER)2, a partir de las cuales analizaremos los orígenes de la terminología matemática en español (muy influida por otras lenguas y culturas coetáneas, como la italiana y la alemana), en la que los mecanismos morfológicos y sintácticos se sugieren fundamentales para la configuración de este tecnolecto.

\section{Corpus}

Nos basamos en el estudio de la voz regla y los compuestos sintagmáticos y combinaciones frecuentes que, a partir de la misma, se documentan en los tratados de aritmética y álgebra más representativos del ámbito hispánico en el periodo renacentista ${ }^{3}$. Cronológicamente dispuestas, las obras objeto de este estudio, pertenecientes al corpus del DICTER — cuya terminología se puede consultar en este diccionario especializado electrónico-, son: Conpusición de la arte de la Arismética y de Geometría (1512) de Juan de Ortega, Libro primero de Arithmética algebrática (1552) de Marco Aurel, Arithmética práctica y speculativa (1562) de Juan Pérez de Moya, Libro de Álgebra en Arithmética y Geometría (1567) de Pedro Núñez Salaciense y Manual de contadores (1589) de Juan Pérez de Moya.

2. Proyecto desarrollado, bajo la dirección de la Dra. Dña. María Jesús Mancho Duque, por el "Grupo de investigaciones lexicográficas y lexicológicas del español moderno y contemporáneo”, reconocido como grupo de investigación de excelencia “GR. 56. Grupo Interuniversitario para el Estudio de la Historia de la Lengua Española (GIEHLE)” por la Junta de Castilla y León, en el Departamento de Lengua Española de la Facultad de Filología de la Universidad de Salamanca y en el Instituto de Estudios Medievales y Renacentistas y humanidades digitales (IEMYRhd).

3. De acuerdo con la consideración de la crítica especializada (cf. Picatoste 1891, Rey Pastor 1926, entre otros). 


\title{
3. Sobre la voz regla
}

Procedente del latín rēgŭla 'regla, barra de metal o madera', según afirman Corominas y Pascual $(D E C H)$, la voz regla se atestigua en el tratado más temprano del corpus analizado, publicado en la primera década del siglo XVI, con la acepción 'modo de formar las cuentas, como sumar, restar, multiplicar y partir' (Autoridades, s. v.) o, según la edición más reciente del diccionario de la docta corporación 'método de hacer una operación matemática' (DLE, s. v.), propia del ámbito de la aritmética, tal y como pone de manifiesto el fraile aritmético, Juan de Ortega, en el siguiente fragmento:

\begin{abstract}
Nota acerca d'esta regla pasada que quandoquiera que en qualquiera resta que venire, agora sea grande o pequenya, en la qual en el renglón de la suma de arriba aya zeros, escomenzando del nombre, y otros tantos abaxo, por quanto yguala el uno con el otro, pondrás zero debaxo de la raya enfruente de cada renglón (1512: fol. 9v).
\end{abstract}

Se destacan, asimismo, métodos o doctrinas consignadas por matemáticos grecolatinos, como los que enumera Euclides en los Elementos, referencia obligada en cualquier texto que verse sobre ciencias exactas publicado en el quinientos, como el compuesto por el alemán Marco Aurel:

El multiplicar de proporciones lo mesmo importa y por la mesma regla se haze que el summar d'ellos, como parece por la 10. ${ }^{a}$ definición del $5^{\circ}$ de Euclides, que dos duplas summadas o multiplicadas hazen una quádrupla; dos triplas summadas o multiplicadas hazen una nóncupla; porque una quádrupla, al presente, es compuesta de dos duplas, y una nóncupla, de tres triplas (1552: fol. 16v).

A menudo, este término recibe modificadores con el fin de especificar qué tipo de operación concreta ha de efectuarse; por ejemplo, la regla del multiplicar (para las multiplicaciones) o regla de partir (para las divisiones), a las que alude Pérez de Moya en su Arithmética práctica y speculativa:

Otro exemplo. Si los 2 tercios de 9 son 2 y medio, ¿qué serán los 3/4 de doce? Toma los 2 tercios de 9, que son 6 , y los 3 quartos de 12, que son 9, y di: si seys, que son los dos tercios de nueve, se tornan en dos y medio, ¿̇en qué se tornarán 9, que son tres quartos de 12 ? Multiplica dos y medio por nueve, por la regla del multiplicar entero y quebrado por entero solo, y montarán 22 y medio. Parte estos 22 y medio a seys, por la regla de partir por 
entero y quebrado a entero solo, y vendrá a la partición 3 y 3 quartos. Y assí, responderás que, si los 2 tercios de 9 son 2 y medio los 3 quartos de 12 serán 3 y 3 quartos (1562: 213).

Se documenta, además, en la época analizada, entre otras, el vocablo regla con sentido filosófico, en la acepción 'precepto, principio o axioma en las ciencias o artes', de acuerdo con la definición sinonímica que promulga el Diccionario de Autoridades académico y como se certifica en el siguiente fragmento del tratado publicado entre 1585-87, bajo el título Varia Commensuración para la Esculptura y Architectura, por el artista de sólida formación matemática Juan de Arphe y Villafañe:

Para que estos principios sean más fáciles a los artífices, para quien escrivimos, que no son mui exercitados en Mathemáticas, dexando las demostraciones de Archímedes, Euclides, Theón y otros, después que imitaron a éstos, usaremos de sus conclusiones como preceptos y reglas $[. .]-$.,

así como con el sentido especializado en el campo de la geometría ( $c f$. Sánchez Martín 2009; DICTER), en la acepción de 'listón recto de madera o de otra materia que sirve para tirar o echar líneas derechas’ que aporta Autoridades $(1737)^{4}$, como se deduce en el final del extracto precedente de la obra de Arphe y Villafañe:

[...] con el compás en la mano y la regla juntamente, que ambos instrumentos an de ser la guía en este primero libro (fol. 2r).

Finalmente, se testimonia en el ámbito de la arquitectura, en un contexto en el que este vocablo podría definirse como 'moldura plana de la que penden las gotas bajo el triglifo en el entablamento dórico’ (cf. DICTER, s. v.), de acuerdo con la imagen y el texto que la acompaña que a continuación reseñamos, ambas pertenecientes a la traducción de Los diez libros de Architectura de A. León Baptista, realizada por el maestro de obras de albañilería y alarife municipal de la villa de Madrid, Francisco de Loçano:

4. En la actualidad, denifinida, desde la edición de 1992 del $D L E$ (s.v.), como 'instrumento rígido y de forma rectangular que sirve para trazar líneas rectas, o para medir la distancia entre dos puntos'. Para una revisión pormenorizada de los cambios en la redacción de la definición de este concepto en los repertorios lexicográficos académicos, véanse NTLLE (s. v. regla) y Mapa de diccionarios académicos (s. v. regla). 


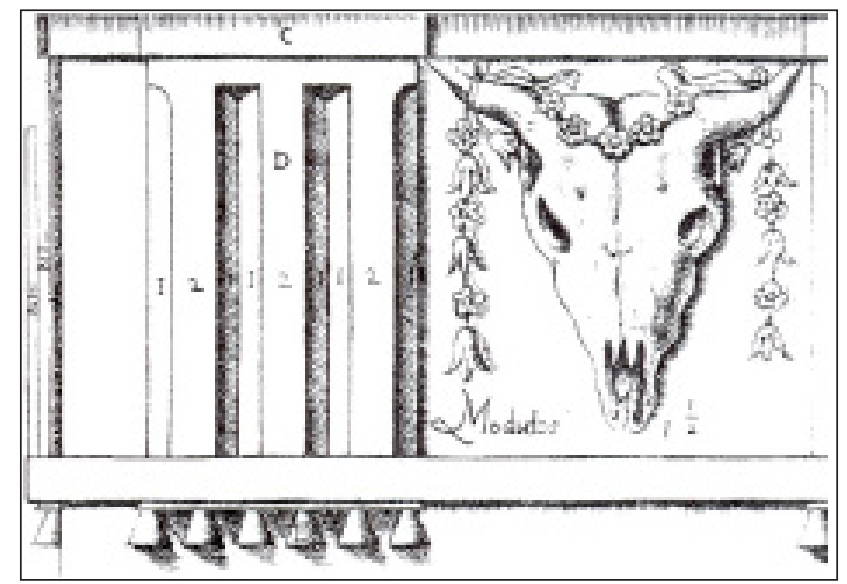

Pero de todos principalmente parece que aprovaron el architrave, en que aya dos faxas, y no más, el qual yo declaro que es dórico, quitadas las reglas y clavillos (1582: 210).

Ahora bien, por lo que respecta al ámbito que nos ocupa, analizaremos y pondremos de manifiesto, en las páginas que siguen, la productividad de esta voz técnica en la creación y trasmisión de una nomenclatura propia del ámbito de la aritmética, por un lado, y del álgebra, por otro, así como en la transición entre las dos disciplinas, la cual refleja, en buena medida, lo que se conoce en la bibliografía especializada como el avance de la aritmética medieval (cuyos vestigios perviven en el Siglo de Oro) al álgebra renacentista.

\subsection{Compuestos con regla en la aritmética comercial}

De acuerdo con Pérez de Moya, la aritmética, en su vertiente práctica, "trata la orden del investigar y hallar los números dudosos demandados, con el auxilio de la qual parte venimos en conoscimiento de lo que se ha de usar acerca de los tractos y mercaderías de la humana vida, para no defraudar ni ser defraudados" (1562: 2), dado que, en la centuria que nos ocupa, el comercio y los intercambios continentales, con los aranceles, los cambios de moneda, etc., y la concepción de cultura matemática como vía burguesa de ascenso y cambio social determinarán, en buena medida, el desarrollo del actual sistema capitalista ${ }^{5}$.

5. El denominado animus lucrandi de la clase burguesa se convierte en el impulso general o primer síntoma del Renacimiento como época de iniciación del capitalismo (apud. Maravall, 1984: 22; Swetz, 1987). 
Así, el objetivo principal y prioritario de las aritméticas estudiadas, las cuales se caracterizan por su pragmatismo y por sus fines eminentemente didácticos, es democratizar un saber, el saber de números (y de los cálculos o cuentas con ellos efectuables), y formar a banqueros, mercaderes y demás profesiones afines a la realidad mercantilista del quinientos, como comprobaremos en los ejemplos seleccionados en las siguientes páginas, en los que se ilustran las instrucciones para llevar a cabo distintos tipos de reglas o métodos aplicados a la aritmética mercantil o comercial:

\subsubsection{Regla de cambiar}

El sustantivo regla, seguido de la preposición de y el verbo cambiar en infinitivo, se atestigua, con la acepción 'método aritmético que enseña a determinar los valores que adquiere una moneda al pasar de un reino o país a otro', al menos desde 1512, en el aritmética confeccionada por el matemático de origen palentino Juan de Ortega, en la que explica:

As de saber que ay dos diferencias acerca de la regla de canbios: la una es que se puede fazer por multiplicar y partir; la otra es que se puede fazer por regla de tres. Y, por tanto, placiendo a nostro Señor, yo pondré acerca de cada una algunos enxemplos brevemente, para que por ellos qualquier portador pueda entender qualquiera regla de cambiar; donde luego quiero poner las diferencias que son por multiplicar y partir, las quales son las siguientes (fol. 93v).

\subsubsection{Regla(s) de cambios}

Como puede leerse en el ejemplo anterior expuesto, esta lexía compleja es, al mismo tiempo, sinónimo de regla de cambios (estructura que se emplea habitualmente en plural), la cual, según Ortega, puede desarrollarse de dos modos:

Como quiera que en las reglas pasadas aya declarado la manera y forma como se a de fazer qualquiera reglas de tres, con tiempo o sin tiempo, ansí por entero como por roto, agora quiero poner aquí adelante algunas reglas de canbios, [...] as de saber que ay dos diferencias acerca de la regla de canbios: la una es que se puede fazer por multiplicar y partir; la otra es que se puede fazer por regla de tres (1512: fol. 93v); 


\subsubsection{Regla de tres (cosas)}

Este testimonio nos lleva, a su vez, a otra forma compuesta a partir de regla; concretamente, la que se refiere al 'método que enseña a determinar una cantidad desconocida por medio de una proporción de la cual se conocen dos términos entre sí homogéneos, y otro tercero de la misma especie que el cuarto que se busca' (DLE, s. v. regla), esto es, una regla de tres. Este concepto se documenta, tanto con variantes alfanuméricas como puramente léxicas, en varias glosas explicativas elaboradas por Juan de Ortega y Juan Pérez de Moya en sus pedagógicos textos ${ }^{6}$ :

As de notar que, para fazer qualquiera regla de tres, siempre pondrás el primero nonbre, que es aquella cosa comprada o vendida, a la man izquierda y la cosa que quieres saber quánto valdrá, a la man derecha. Y el precio de la primera, esa que se a comprado o vendido, qu'es el contrario de los dos nonbres, pondrás en medio de los dos nombres semejantes. Y quando ansí tuvieres asentados los tres nonbres, multiplica el nonbre que está a man derecha, que es aquello que quieres saber qué valdrá, por el nonbre que está en medio, que es el contrario, y aquella suma que saliere por la tal multiplicación pártela por el otro semejante, que es el nonbre que está a la man izquierda. Y aquello que saliere por la tal partición será el valor de aquella cosa que quieres saber quánto valdrán o será vendida, conviene a saber, el nonbre de a man derecha (1512: fol. 76v).

Ya que por algún modo ayas entendido, de los tres números que en la regla de 3 concurren, quál es primero, quál segundo y quál tercero, y esto por fin de saber quáles d’ellos son los que han de multiplicar y quál d'ellos es el que ha de partir, tienes necessidad de advertir ciertas concordancias, que, si no las guardas, errarás fácilmente y dirás disparates en lugar de respuesta (1589: fol. 147r).

\subsubsection{Con los modificadores llana, simple o el complemento sin tiempo}

No obstante, la regla de tres variará en función de las cantidades o el valor de monedas, sin tener en cuenta el tiempo que las mismas han servido, entre los tres términos de la proporción mediante la que se halla, amplicando este método, la cantidad desconocida. Esta restricción semántica se verbalizará mediante el uso

6. Según Gómez (2006: 51), "la metodología de enseñanza se sustentaba en la idea que el aprendizaje de la regla de tres era una cuestión de adiestramiento en torno a ciertos ritos relacionados con el empleo de palabras clave, el orden de los términos, la disposición práctica de los datos numéricos, el método de resolución y la secuencia de presentación de las ideas”. 
de los modificadores llana, simple o el complemento sin tiempo en aposición a la forma compleja objeto de estudio, como puede leerse en los siguientes ejemplos:

Agora, multiplica en cruz A con B, y vernán 128, y será el primero seys meses en medio; y luego C con D, y vernán 48, el qual será el $3^{\circ}$ número de la regla de tres llana, y verná: si 128 ganan o dan seys, ¿qué darán 48? y vernán en la partición 2 1/4; en tantos meses ganan 16 ducados 4 ducados, como en la passada has visto (Aurel 1552: fol. 24v).

Sigue la orden de la regla de tres simple o sin tiempo, multiplicando 750000 por 1000, y montarán 750000000. Parte esta multiplicación por los 5000000 y vendrá a la partición 150. Tantos maravedís salen al millar. Lo qual sabido, si una dignidad o capellán tiene 30000 maravedís de renta, cuéntenle, por cada mil, 150 maravedís; quiero dezir que multipliques 30, que son los millares d'esta capellanía, por 150 que sale a cada uno, y lo que cupiere es lo que se deve: 30000 mil (Pérez de Moya 1589, fol. 171r).

\subsubsection{Con el modificador mixta o el complemento con tiempo}

Por el contrario, con el modificador mixta o el complemento con tiempo se consigna de manera exclusiva en el Manual de contadores redactado por Pérez de Moya en 1589, con el valor de 'método que enseña a determinar una cantidad desconocida por medio de una proporción de la cual se conocen más de tres términos entre sí distintos, referidos principalmente a las cantidades o valor de monedas y al tiempo que las mismas han servido', tal y como se deduce del siguiente fragmento explicativo:

Regla de tres mixta o con tiempo dizen a la que trae más de tres números o quantidades distintas, como diziendo: si 100 ducados, en doze meses, ganan 8 ducados, pido: 170 ducados, en 5 meses, ¿qué ganarán o rentarán al mismo respeto? En estas semejantes qüestiones multiplicarás las quantidades de monedas que traxeren tiempo con su mismo tiempo que sirvió, o han de servir (fol. 156v).

De manera análoga, testimoniamos en una única ocasión y en uso metalingüístico, en la aritmética de Ortega integrada en el corpus estudiado, la variante analítica del compuesto regla de tres analizado, la cual se construye con el término cosa, con el valor número o cantidad, hoy extinta: 
El onzeno capítulo de la Arismética se llama regla de tres cosas, por la qual regla puede muy prestamente qualquier contador fazer qualquiera cuenta que sea, sin la qual nenguno puede saber contar cosa nenguna. Y, por tanto, dándome Dios gracia, yo entiendo de dar breve manera para declarar qualquiera cuenta que sea que venga por regla de tres, por sano o por roto, con tiempo o sin tiempo. Acerca de lo qual as de notar que en qualquiera razón de mercadurías son necesarios tres nonbres (fol. 76r).

\title{
3.1.4. Regla de compañía
}

De acuerdo con el $D L E$, documentamos la forma compleja creada a partir del término regla y la voz compañía precedida de la preposición de, con la acepción de método 'que enseña a dividir una cantidad en partes proporcionales a otras cantidades conocidas, empleada principalmente para la distribución de ganancias o pérdidas entre los socios de una compañía comercial con arreglo a los capitales aportados por cada uno', tal y como ilustra, al lector no versado, Juan de Ortega:

\begin{abstract}
Si quisieres saber qué cosa es regla de compañía, as de saber que no es otra cosa sino un ayuntamiento de dinero que se faze entre muchas o pocas personas para ganar su vida. Y, después, aquella que se gana con los dineros que todos an puesto, saber quánto vendrá a cada uno, según lo que puso o el tiempo que a estado en la compañía, como lo verás en los enxemplos siguientes (fol. 109v).
\end{abstract}

Un problema canónico que contiene este tipo de operación aritmética es el siguiente, enunciado por Juan Pérez de Moya:

Ordena una regla de compañía, diziendo: tres hazen compañía: el primero pone doze; el segundo 8, el tercero 6. Ganaron 78 (que son los ducados que cuesta la heredad). Pídese: ¿qué vendrá a cada uno? Sigue la regla de compañía summando lo que todos ponen (que en este exemplo son 12, 8 y 6) y montarán 26, y di por la regla de 3: si 26, que es lo que todos pusieron, ganaron o perdieron 78 , ¿qué vendrá de ganancia o pérdida al que puso 12 ? (1562: 248).

Como explica Navarro Loidi (2006), este tipo de método fue consignado por primera vez en las aritméticas publicadas a finales del Medievo7, pero, con el

7. "En un comienzo los problemas sobre la adjudicación de beneficios en un negocio no se distinguían de otras cuestiones sobre el reparto proporcional que se solían introducir como aplicaciones 
fin de suplir las necesidades contables de mercaderes y banqueros, comenzaron a incluirse, como un capítulo más, en las aritméticas renacentistas, en las que figuran multitud de problemas con el enunciado clásico de regla de compañía.

Ahora bien, de manera análoga a las reglas de tres, existen dos subtipos principales de reglas de compañía que, a continuación, analizamos sucintamente:

\subsubsection{Con los modificadores Ilana, simple o con el complemento sin tiempo}

Documentamos esta lexía compleja, con los modificadores llana, simple o con el complemento sin tiempo, para referirse al método 'que enseña a dividir una cantidad en partes proporcionales a otras cantidades conocidas, empleada principalmente para la distribución de ganancias o pérdidas entre los socios de una compañía comercial con arreglo a los capitales aportados por cada uno durante un mismo periodo de tiempo'. En el Manual de contadores de Pérez de Moya se registran varios ejemplos que ilustran tanto el encabezamiento de este género de problemas como las pautas o instrucciones que explican el modo de desarrollarlos:

ordena una regla de compañía llana, diziendo: tres hazen compañía: el uno puso 20, el segundo 35, el tercero 45. Gastaron 40 ducados. Pido: ¿qué dará cada uno? Para hazerla, passa al capítulo precedente (1589: fol. 166r).

El uno puso 200 y el otro 120. Ganaron 50 ducados. Demándase, ¿qué viene d’esta ganancia a cada uno? Sigue la regla de compañías simple o sin tiempo que pusimos en el capítulo tercero, y vendrán al primero 31 ducados y un quarto de ducado, y al segundo 18 ducados y tres quartos. Y assí se harán las semejantes (1589: fols. 166r-166v).

\subsubsection{Con el modificador mixta o el complemento con tiempo}

Por el contrario, con el sentido de regla 'que enseña a dividir una cantidad en partes proporcionales a otras cantidades conocidas, empleada principalmente para la distribución de ganancias o pérdidas entre los socios de una compañía comercial con arreglo a los capitales aportados por cada uno en distintos periodos de tiempo', aparece acompañada por el modificador mixta o el complemento con

de la regla de tres [...]. Sólo al final de la Edad Media la regla de compañía comenzó a figurar habitualmente entre los problemas de repartos proporcionales, a distinguirse de otras cuestiones similares y a conocerse por su nombre” (Navarro Loidi 2006: 117). Para un análisis exhaustivo de la aplicación de las reglas de compañía en las aritméticas españolas renacentistas, véase Labarthe (2005). 
tiempo, como se certifica en el siguiente fragmento extraído de la Arithmética práctica y speculativa:

\begin{abstract}
Exemplos de la regla de compañía, que dizen mixta o con tiempo: En estos exemplos de regla de compañía con tiempo has de multiplicar primero el tiempo de cada uno con su dinero, y después hazer con los productos lo mismo que heziste en la simple o sin tiempo. Exemplo. 2 hizieron compañía: el primero puso 10 ducados y 8 meses; el segundo dio 14 ducados y 12 meses; ganaron con este dinero y tiempo 744 reales. Pídese: ¿qué vendrá a cada uno de la ganancia, según el tiempo y dinero que puso? Multiplica primero los 10 ducados del primero por su 8 meses que puso y montarán 80; guarda estos 80. Assimismo, multiplicarás los 14 ducados del segundo por sus 12 meses y montarán 168. Aora di: 2 hazen compañía, el primero puso 80 entre dineros y tiempo; el segundo puso 168; ganaron 744. Demando: ¿qué viene a cada uno? Sigue la regla de compañía simple, según hemos mostrado, y vendrá al primero $240 \mathrm{y}$ al segundo 504 . Y porque todo se reduze a la regla de 3, en esto no quiero ser prolixo (1562: 244).
\end{abstract}

\title{
3.1.5. Las cuatro reglas
}

Finalmente, compuesta mediante la anteposición del adjetivo numeral cardinal cuatro, testimoniamos la lexía compleja que da nombre al conjunto de las operaciones básicas de la aritmética, que son: sumar, restar, multiplicar y dividir; dos pares que se oponen, esto es, "se hazen cada una por su contraria; quiero dezir el summar se prueva por el restar y el restar por el summar; el multiplicar por el partir y el partir por el multiplicar” (1562: 507), cuyo conocimiento es, en palabras de Pérez de Moya, “cosa muy necessaria para el servicio de la vida humana y digna de ser sabida de todo hombre que desseare ser puesto en el número de los que sienten d'esta razón” (1562: X).

\subsection{De la aritmética al álgebra}

En el avance que va de la aritmética medieval al álgebra renacentista, como en toda transición, existe una zona de intersección en la que hallamos un par de métodos matemáticos que están a medio camino entre las dos disciplinas: las reglas de falsa posición. Estos métodos de tradición árabe y de origen egipcio (documentada ya, según Orts [2007, cf. Gillings 1982], en los problemas 24 y 27, papiro de Rhind, 1650 a. C., de donde la tomaron los matemáticos indios), 
gozaron de gran éxito y popularidad en las aritméticas mercantiles del siglo $\mathrm{XV}$, en las que se trataron exhaustivamente, "conduciéndolos hasta las mismas puertas del álgebra” (apud. Paradis/Malet 1989). Como certifica Meavilla (2001: 134), en general, esta regla "se usaba para resolver algunos problemas de primer grado con una incógnita, sin necesidad de recurrir al simbolismo algebraico”, de mayor complejidad.

\subsubsection{Regla de (una) falsa posición}

Esta lexía compleja que parte del núcleo regla, al que se adosa el complemento de falsa posición -ocasionalmente contabilizado, por oposición a regla de dos falsas posiciones, por el adjetivo numeral uno en uso fenemino-, fue introducida en Occidente como il método de falsa posizione (o regola falsi) en 1202, cuando se registra en la tercera parte del duodécimo capítulo del Liber Abaci del matemático italiano prerrenacentista Leonardo de Pisa (alias Fibonacci). Esta se podría definir como el método 'que enseña a resolver algunos problemas por medio de un número supuesto falso, del que se deduce el valor de la incógnita tras compararlo con los datos del problema' (ax=b), de acuerdo con las doctrinas del matemático palentino:

has de saber que [regla de] falsa posición no quiere dezir otra cosa, sino que para saber fazer qualquiera cuenta que no sepas, que fingiendo por esta regla lo que no es cierto, podrás saber aquello que es cierto, como verás en las reglas siguientes (Ortega 1512: fol. 171r).

Igualmente, tanto Aurel como Pérez de Moya explican en sus tratados, mediante sendas glosas explicativas, la naturaleza y la denominación de este tipo de método popular constituido por operaciones aritméticas aplicadas a la resolución de planteamientos algebraicos; concretamente, ecuaciones numéricas lineales:

Esta regla de falsa posición no es otro que poner un número y no aquél que ha de ser; y si es, como digo, otro, será número falso, de adonde toma la denominación la dicha regla llamarse posición falsa; con el qual siguirás conforme a la demanda como si fuere el propio número verdadero, hasta tanto que vengas a la fin y acabar la demanda, y verás que no viene aquello que demandastes. Assí, proporcionarás el dicho número falso puesto con el que te havía de venir, por donde te venga el número verdadero y desseado, como por exemplo verás (1552: fol. 31r). 
Dízese regla de una falsa posición, no porque nos muestre cosa falsa, sino porque de falso número sacamos un verdadero para fin de absolver alguna dubda demandada. Y assí digo que quando te demandaren alguna demanda presupondrás un qualquiera número por respuesta de la demanda, con el qual número harás lo que la demanda pidiera, como quien quisiesse hazer la prueva, y si no viniere lo que quisieres, proporcionarás el número que te viniere con el que quisieres que viniera, y siguiendo la regla de tres hallarás el número verdadero (1562: 273).

\subsubsection{Regla de dos falsas posiciones}

Por su parte, la voz regla junto con el numeral cardinal dos y el complemento falsa posición (en plural), del italiano regola di doppia falsi posizione documentado, igualmente, por vez primera en 1202, en el capítulo 13 del Liber Abaci de Fibonacci (quien también la denominaba elchataym, del árabe hisab al-Khataayn, Orts 2007: 57), se atestiguará, con el valor de método 'que enseña a resolver algunos problemas por medio de dos números supuestos falsos, de los que se deduce el valor de la incógnita tras compararlos con los datos del problema', en las aritméticas renacentistas, como se aprecia en las siguientes operaciones detalladas en la obra de Marco Aurel:

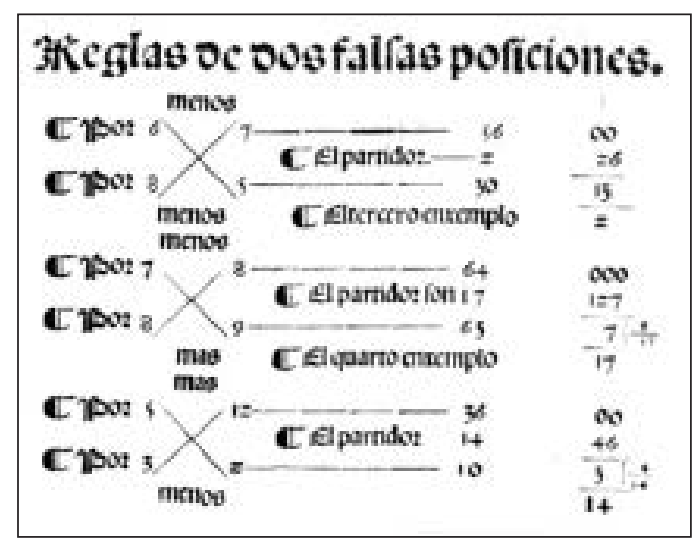

En la regla de 2 falsas posiciones lo mesmo harás, como con la una falsa has visto, en poner un número falso, con el qual siguirás conforme a la demanda. Y, a la postre, mira si lo que viene es más o menos de lo que havía de ser. Aquello pornás aparte al costado del número falso, a su mano derecha, con el señal de más o menos, qual fuere, digo, la differencia que havrá de lo que vino a lo que havía de venir (1552: fol. 31v). 


\subsection{Compuestos con regla en el álgebra}

Por lo que respecta a la productividad del término regla en el ámbito del álgebra, se registra una pluralidad denominativa para dar voz a la 'parte de las matemáticas en la cual las operaciones aritméticas son generalizadas empleando números, letras y signos. Cada letra o signo representa simbólicamente un número u otra entidad matemática. Cuando alguno de los signos representa un valor desconocido se llama incógnita' ( $D L E$, s. v. álgebra), es decir, para dar nombre a la propia disciplina, motivada por una serie de cuestiones históricas y socioculturales que, en las siguientes páginas, esbozamos.

\subsubsection{Regla de(l) álgebra}

En primer lugar, a partir de la voz regla y el arabismo álgebra ${ }^{8}$, como complemento preposicional introducido por de y como especificador que erige un subtipo de regla o método, atestiguamos el compuesto sintagmático regla de(l) álgebra en una enumeración en la que se detallan otros vocablos o formas complejas de creación patrimonial que, en el Renacimiento, eran empleados, como certifica el jienense Pérez de Moya, para dar nombre a este concepto matemático:

Diversos nombres tiene esta Regla acerca de varios authores. Unos la llaman Regla de Álgebra, que quiere dezir restauratio, o almucábala, que quiere dezir opposición o absolución, porque por ella se hazen y absuelven infinitas qüestiones (y las que son impossibles nos las demuestra) assí de Arithmética como de Geometría, como de las demás artes (que dizen) mathemáticas (1562: 448);

“vulgarmente llamada Arte mayor o regla de la cosa”, como señala el alemán Marco Aurel en el título de su libro, el primero publicado en la Península Ibérica sobre esta materia abstracta.

8. Del árabe ğabr 'reducción', perteneciente a la raíz $\breve{g}-b-r$ 'reforzar', 'curar', 'restituir'. En la traducción del ár. 'ilm al-ğabr wa l-muqābala 'ciencia de las reducciones y de las comparaciones' (DECH). En palabras de Bell (2000: 109), al-jabr w’almuqābala significa “restauración y reducción, aludiendo a lo que ahora se llama transposición de términos negativos, para producir ecuaciones con todos sus términos positivos, y a la subsiguiente reducción simplificando los términos de igual potencia de la incógnita”. 


\subsubsection{Regla de la cosa}

Como se aprecia en la apostilla de Aurel, a partir del vocablo regla y el complemento cosa (derivado de la adaptación al latín del término técnico árabe [transliterado shay'], empleado para designar la incógnita, en el simbolismo algebraico actual representada por la $x$ ), se genera el compuesto sintagmático regla de la cosa como designación popular renacentista para dar nombre a la ciencia que trata sobre las incógnitas, es decir, el álgebra indoarábiga.

\subsubsection{Regla(s) real(es)}

Asimismo, se registra la lexía compleja reglas reales con este valor, sinónimo, por tanto, de los compuestos precedentes, como remarca Pérez de Moya en el índice de su Aritmética: "Reglas reales es lo mismo que Regla de la cosa” (1562: XXXV).

\subsubsection{Regla de la segunda cosa}

Sin embargo, el progreso de esta vertiente de las matemáticas se tradujo en estructuras y problemas de mayor complejidad, para cuya resolución eran necesarias, igualmente, ecuaciones de planteamiento cada vez más complejo, como el que representan el concepto de la segunda cosa o doble incógnita y el compuesto sintagmático regla de la segunda cosa. De hecho, esta forma compleja, constituida por el sustantivo regla y el adjetivo numeral ordinal segunda antepuesto al núcleo cosa 'incógnita', fue la designación de la que comúnmente se sirvieron los algebristas hispanos para dar nombre al método que enseña a resolver sistemas de ecuaciones lineales de dos o más incógnitas. Como puede apreciarse en el siguiente ejemplo de Pérez de Moya, este método supone una ampliación de la regla de la cosa, ya que, según los matemáticos del siglo $\mathrm{XVI}$, esta última resulta, en algunos casos, insuficiente y, por ello, se requiere la presencia de un elemento auxiliar: la segunda cosa (en notación algebraica actual: y).

\footnotetext{
Artículo nono d'este XIII capítulo. Trata de la regla de la segunda cosa o quantidad: En esta regla, por la mayor parte, se pone una cosa por respuesta de la demanda (como se ha visto en los capítulos precedentes), mas ay muchas demandas que para venir a su última respuesta es necessario poner otra posición; y porque la segunda posición se differencie de la primera,
} 
ponen una quantidad que se figura d'esta manera: 1q., con la qual se procede haziendo lo que la demanda pide hasta tanto que se haga una igualación (1562: 599-600).

\subsubsection{Regla de la cantidad}

Esta forma compleja, sinónimo de regla de la segunda cosa, procede de la traducción del compuesto sintagmático italiano regola della quantità, empleado por primera vez en las últimas décadas del siglo XIV por el matemático florentino Antonio de Mazzinghi, en su Trattato di fioretti (ca. 1380). El término cantidad -atestiguado, por lo general, con la variante gráfica quantidad-, responde a la necesidad de introducir una incógnita adicional, distinta e independiente de la cosa, que, de acuerdo con las explicaciones de los algebristas del Renacimiento, debe ser inserta también en una posición distinta dentro del algoritmo de la ecuación que se pretende resolver, tal y como puede leerse en el siguiente fragmento extraído de la obra de Aurel:

Esta regla de la quantidad enseña cómo te has de haver con algunas demandas, que con solo poner la co. no basta a llegar a la ygualación y última respuesta, como en las passadas, como muchas vezes acontesce se aya de poner otra posición o otras para que puedas venir a la fin desseada (1552: fol. 108r).

\subsubsection{Con los modificadores absoluta o simple}

Finalmente, consignamos, de modo exclusivo en Libro de Álgebra (1567) de Núñez Salaciense, una especificación de la cantidad (o segunda incógnita, y), representada por los compuestos regla de la cantidad simple o absoluta. A través de estas denominaciones, el matemático luso se propone distinguir las cantidades que se hallan en una continua proporción o progresión geométrica (dupla, tripla, cuádrupla, etc.), que habitualmente caracterizan a la cosa (o incógnita, $x$ ) y sus sucesivas potencias, de las que conforman a la cantidad simple o absoluta, tal y como puede verificarse en el fragmento que a continuación exponemos:

La regla de la quantidad simple o absoluta nos es distincta de las otras, y usamos d'ella en dos maneras. La primera es un suplimiento en las Reglas de la cosa para hazermos la ygualación con ayuda d'este término quantidad, porque, puesto que las otras dignidades 
también sean quantidades, no son, pero, absolutas, sino respectivas las unas comparadas a las otras por el modo que avemos dicho (fol. 222v) ${ }^{9}$.

\section{Conclusiones}

Como se ha puesto de manifiesto, la voz regla se erige como un núcleo rentable para la creación de una serie de formas complejas relativas a la aritmética y el álgebra y a su desarrollo. Por lo que respecta a los testimonios matemáticos del quinientos español, atestiguamos, diseminadas en las obras de Ortega, Aurel, Pérez de Moya y Núñez Salaciense, una veintena de tecnicismos referidos a ambas disciplinas y a la transición que entre ellas se da, en la que asistimos al cambio del enfoque metodológico, constituido por el paso del método de resolución aritmético al método de resolución algebraico en España.

Entre los compuestos sintagmáticos documentados destacan, por su aplicación práctica a las necesidades contables de la época -demandadas por el incipiente y raudo desarrollo comercial-, las reglas de aritmética básica, esto es, el dominio de las cuatro reglas u operaciones matemáticas elementales (sumar, restar, multiplicar y dividir), las reglas de cambios (fundamentales para las transacciones internacionales y sus inexcusables implicaciones monetarias), las reglas de tres (aplicadas a la compra/venta de distintos productos) y las reglas de compañía (para el reparto proporcional de los beneficios entre los socios capitalistas de compañía comercial) de variada índole. En efecto, este último binomio de lexías complejas presentan, mediante los complementos o pares opuestos con / sin tiempo, simple o llana / mixta, tal y como se ha procurado plasmar en los fragmentos extraídos de las aritméticas hispánicas del siglo XVI -en los que se hallan una buena colección de problemas de reglas de tres y de reglas de compañía-, unas especificaciones de vital relevancia para la ejecución de este tipo de operaciones especializadas.

Por otro lado, a medio camino entre el arte menor (aritmética práctica) y el arte mayor (álgebra), atestiguamos los métodos de falsa posición para la resolución de ecuaciones lineales de valor cualquiera: regla de (una) falsa posición o de dos

9. “En estas líneas Núñez enfatiza el carácter absoluto de esta cantidad ignota concreta (y), como un elemento auxiliar independiente empleado para la resolución de ciertas ecuaciones, por lo que, en este caso, no adquiere o presenta un valor relativo ni vinculado al valor de otros números incógnitos pedidos (como sucede con la cosa $>x$ y las sucesivas potencias de la misma: censo $>x^{2}$, cubo $>x^{3}$, etc.), de cuyo valor o cantidad atribuida depende el del resto de las potencias de la incógnita” (Molina Sangüesa, 2015b: 140). 
valores cualquiera: regla de dos falsas posiciones, las cuales penetran al español a través del italiano, a partir de los influyentes tratados confeccionados por Leonardo de Pisa y Luca Pacioli. Sin embargo, con la aparición del álgebra y su difusión en Occidente, los métodos algebraicos fueron sustituyendo paulatinamente a estos, hasta relegarlos a meros métodos de aproximación particulares.

Por lo que respecta a la disciplina abstracta analizada, el álgebra, registramos los métodos que enseñan a resover una (regla de la cosa) o más (regla de la segunda cosa, regla de la cantidad) incógnitas, así como una pluralidad denominativa referida a la propia ciencia (álgebra, regla del álgebra, reglas reales, etc.) que, a diferencia de las formas complejas referidas a la aritmética, no se consignan en los repertorios lexicográficos del español y que hoy se consideran extintas del correspondiente tecnolecto matemático hispánico. De nuevo, la intertextualidad con la Suma de Pacioli es evidente en la proliferación de esta nomenclatura en un estadio emergente de esta ciencia en la Península Ibérica, la cual presentaba, a su vez, una complejidad añadida: el dominio del incipiente simbolismo algebraico (aún en fase sincopada).

En suma, consideramos que el término regla genera una red léxica amplia y rica en matices, de relevancia filológica e historico-cultural apenas estudiada, de la que esperamos haber arrojado alguna luz en este análisis.

\section{Bibliografía}

ARPHE Y VILLAFAÑE, J. (1585-87). De varia commensuración para la Esculptura y Architectura. Sevilla: Andrea Pescioni y Juan de León.

AUREL, M. (1552). Libro primero de Arithmética algebrática. Valencia: Joán de Mey.

BAPTISTA, L. (1582). Los diez libros de Architectura (Trad. F. Loçano). Madrid: Alonso Gómez.

BELL, E. T. (2000). Historia de las matemáticas. México: Fondo de Cultura Económica.

COROMINAS, J. y PACUAL, J. A. (1980-1991). Diccionario Crítico Etimológico Castellano e Hispánico. Madrid: Gredos. (DECH).

DE PISA, L. (Fibonacci) (1202). Liber Abaci.

GILLINGS, R. (1982). Mathematics in the time of the pharaons. New York: Dover Publications.

GÓMEZ, B. (2006). "Los ritos en la enseñanaza de la regla de tres”. En José Mariano Vallejo, El Matemático Ilustrado. Una mirada desde la educación 
matemática (Eds. A. Maz, M. Torralbo y L. Rico). Córdoba: Servicio de Publicaciones de la Universidad de Córdoba: 47-69.

HUGHES, B. (1986). "Gerard of Cremona's Translation of al-Khwārizmī's Aljabr: A Critical Edition”. Mediaeval Studies 48: 211-263.

INSTITUTO DE INVESTIGACIÓN RAFAEL LAPESA DE LA REAL ACADEMIA ESPAÑOLA (2013-). Mapa de diccionarios. Disponible en: $<$ http://web.frl.es/ntllet> [Acceso: 07/07/2018].

LABARTHE, M. H. (2005). "Les règles de compagnie, dans les premières arithmétiques imprimées des Espagnes: de la règle marchande à l'outil mathématique". Revue d'histoire des mathématiques 11: 257-313.

MANCHO, M. J. (dir.) (en línea). Diccionario de la Ciencia y de la Técnica del Renacimiento. Salamanca: Ediciones Universidad de Salamanca. Disponible en: <http://dicter.eusal.es/> [Acesso: 10/11/2017]. (DICTER).

MARAVALL, J. A. (1972). Estado moderno y mentalidad social. Madrid: Revista de Occidente.

MARAVALL, J. A. (1984). Estudios de historia del pensamiento español. La época del Renacimiento. Madrid: Ediciones Cultura Hispánica.

MAZZINGHI, A. (1380). Trattato di Fioretti nella trascelta a cura di $M^{\circ}$ Benedetto (Ed. G. Arrighi [1967]). Pisa: Domus Galileana.

MEAVILLA, V. (2001). Aspectos históricos de las matemáticas elementales. Zaragoza: Prensas Universitarias de Zaragoza.

MOLINA SANGÜESA, I. (2015a). "Glosario de aritmética y álgebra en el Renacimiento hispano”. En Diccionario de la Ciencia y de la Técnica del Renacimiento (Dir. M. J. Mancho). Salamanca: Ediciones Universidad de Salamanca. Disponible en: <http://dicter.usal.es> [Acceso: 10/11/2017] (DICTER).

MOLINA SANGÜESA, I. (2015b). "En torno a las incógnitas del álgebra: cosa, segunda cosa y cantidad. Análisis de una terminología matemática renacentista”. Lexicografía, fraseología y terminología (Coords. J. A. Pascual y E. Liverani), Monografía Cuadernos AISPI 6: 127-147.

NAVARRO LOIDI, J. (2006). "La regla de compañía y la didáctica del reparto proporcional”. Sigma 28: 117- 130.

NÚÑEZ SALACIENSE, P. (1567). Libro de Álgebra en Arithmética y Geometría. Anvers: Herederos de Arnoldo Birckman.

ORTEGA, J. (1512). Conpusición de la arte de la Arismética y de Geometría. Lyon: Maistro Nicolau de Benedictis (por Joannes Trinxer).

ORTS, A. (2007). "Resolución de problemas mediante la regla de falsa posición: un estudio histórico”. Suma 56: 55-61. 
PARADIS, J. y MALET, A. (1989). Los orígenes del álgebra: de los árabes al Renacimiento. Barcelona: Promociones y Publicaciones Universitarias (PPU).

PÉREZ DE MOYA, J. (1562). Arithmética práctica y speculativa. Salamanca: Mathías Gast.

PÉREZ DE MOYA, J. (1589). Manual de contadores. Madrid: Pedro Madrigal.

PICATOSTE, F. (1891). Apuntes para una biblioteca científica española del siglo XVI. Madrid: Imprenta y Fundación Manuel Tello.

REAL ACADEMIA ESPAÑOLA (1726-39 [1990]): Diccionario de Autoridades. Madrid: Gredos.

REAL ACADEMIA ESPAÑOLA (2001): Nuevo Tesoro Lexicográfico de la Lengua Española (edición DVD). Madrid: Espasa Calpe. Disponible en: $<$ http://ntlle.rae.es> [Acceso: 10/11/2017] (NTLLE).

REAL ACADEMIA ESPAÑOLA (2014). Diccionario de la lengua española. Madrid: Espasa Calpe. Disponible en: <http:// http://dle.rae.es/> [Acceso: 10/11/2017] (DLE).

REY PASTOR, J. (1926). Los matemáticos españoles del siglo XVI. Madrid: Biblioteca Scientia.

SÁNCHEZ MARTÍN, F. J. (2009). Estudio del léxico de la geometría aplicada a la técnica en el Renacimiento hispano. Salamanca: Ediciones Universidad de Salamanca.

SWETZ, F. J. (1987). Capitalism and Arithmetic: The new math of the $15^{\text {th }}$ century. La Salle, Illinois: Open Court. 